\title{
The New Stapler Device Is Good, But Needs More Evaluation
}

\author{
Young Wan Kim, Ik Yong Kim \\ Department of Surgery, Yonsei University Wonju College of Medicine, Wonju, Korea
}

See Article on Page 77-82

In colorectal surgery, safe anastomosis following complete tumor removal is an essential element. Colorectal surgeons inevitably encounter anastomosis-related complications, such as leakage, stenosis, or bleeding. Anastomosis leakage is associated with not only poorer short-term clinical outcomes, but also unfavorable oncologic outcomes [1]. In addition, anastomosis stenosis compromises the patient's quality of life.

The use of the circular stapler has facilitated sphincter-preserving surgery for sigmoid colon or rectal cancer, and the stapling technique has become popular. However, that stapler device does not always guarantee a $100 \%$ safe colo-colic or colo-rectal anastomosis. In this regard, a compression anastomosis device (Colon Anastomosis Ring-ColonRing, NiTi Surgical Solutions, Netanya, Israel) has been introduced. However, small-scale animal and human studies have shown comparable results between stapled and compression anastomosis [2]. In this issue of the Annals of Coloproctology, Kwag et al. [3] published their retrospective data. The authors evaluated the safety and efficacy of the compression anastomosis device in 67 colon cancer patients and observed that the compression anastomosis device did not increase the incidence of anastomosis-related complications. This type of study, which investigates a new surgical device, always deserves to be applauded as new techniques carry unknown risks and a learning curve. However, this study was based on a retrospective, small series and only included data on colon cancer patients. In a recent study, Kang et al. [4] evaluated a total of 20 cases of compression anastomosis (anterior resection, 11; low anterior resection, 9) and experi-

Correspondence to: Ik Yong Kim, M.D.

Department of Surgery, Yonsei University Wonju College of Medicine,

20 Ilsan-ro, Wonju 220-701, Korea

Tel: +82-33-741-0573, Fax: +82-33-744-6604

E-mail address: iykim@yonsei.ac.kr

(c) 2014 The Korean Society of Coloproctology

This is an open-access article distributed under the terms of the Creative Commons Attribution NonCommercial License (http://creativecommons.org/licenses/by-nc/3.0) which permits unrestricted noncommercial use, distribution, and reproduction in any medium, provided the original work is properly cited. enced one anastomosis leakage in patients with rectosigmoid colon cancer. The compression anastomosis technique needs more large-scale clinical studies and more data on rectal cancer surgery before it will be accepted.

A bad workman finds fault with his tools. For good gastrointestinal anastomosis, strict adherence to operative principles may be more important than the type of surgical device used. These principles include adequate exposure of the surgical field, the use of well-vascularized tissue, absence of tension, no fecal contamination, watertight closure, mucosal apposition and meticulous technique [5].

\section{REFERENCES}

1. Jung SH, Yu CS, Choi PW, Kim DD, Park IJ, Kim HC, et al. Risk factors and oncologic impact of anastomotic leakage after rectal cancer surgery. Dis Colon Rectum 2008;51:902-8.

2. Zbar AP, Nir Y, Weizman A, Rabau M, Senagore A. Compression anastomoses in colorectal surgery: a review. Tech Coloproctol 2012; 16:187-99.

3. Kwag SJ, Oh ST, Kim JG, Kang WK, Lee JK. Niti CAR 27 versus a conventional end-to-end anastomosis stapler in a laparoscopic anterior resection for sigmoid colon cancer. Ann Coloproctol 2014;30: 77-82.

4. Kang J, Park MG, Hur H, Min BS, Lee KY, Kim NK. Safety and efficacy of the NiTi Shape Memory Compression Anastomosis Ring (CAR/ColonRing) for end-to-end compression anastomosis in anterior resection or low anterior resection. Surg Innov 2013;20: 164-70.

5. Silberstein I, Rolandell R. Suturing, stapling, and tissue adhesives. In: Yeo CJ, editor. Shackelford's surgery of the alimentary tract. 7th ed. Philadelphia: Elsevier Inc.; 2012;920-8. 